\title{
IMPLEMENTASI MANAJEMEN KURIKULUM PADA PENDIDIKAN ANAK USIA DINI SULAPA EPPA
}

\author{
Umi Kusyairy \\ Jurusan Pendidikan Islam Anak Usia Dini \\ Fakultas Tarbiyah dan Keguruan, UIN Alauddin Makassar \\ E-mail: umi.kusyairi@uin-alauddin.ac.id \\ Ika Dewi Sartika \\ Jurusan Pendidikan Islam Anak Usia Dini \\ Fakultas Tarbiyah dan Keguruan, UIN Alauddin Makassar \\ E-mail: 20900116018@uin-alauddin.ac.id \\ Husnul Hidayah \\ Jurusan Pendidikan Islam Anak Usia Dini \\ Fakultas Tarbiyah dan Keguruan, UIN Alauddin Makassar \\ E-mail: 20900116007@uin-alauddin.ac.id

\section{Sri Hartati} \\ Jurusan Pendidikan Islam Anak Usia Dini \\ Fakultas Tarbiyah dan Keguruan, UIN Alauddin Makassar \\ E-mail:20900116011@uin-alauddin.ac.id \\ Nurhidayat \\ Jurusan Pendidikan Islam Anak Usia Dini \\ Fakultas Tarbiyah dan Keguruan, UIN Alauddin Makassar \\ E-mail: 20900116019@uin-alauddin.ac.id
}

\begin{abstract}
Abstrak
Penelitian ini bertujuan untuk mengetahui proses perencanaan, pelaksanaan atau penerapan, dan pengembangan kurikulum di Pendidikan Anak Usia Dini (PAUD) Sulapa Eppa Jenis penelitian ini menggunakan penelitian deskriptif kualitatif. Subjek penelitian adalah kepala sekolah PAUD Sulapa Eppa. Pengumpulan data dilakukan melalui teknik indepth interview, observasi dan angket. Hasil penelitian menunjukkan: 1) Perencanaan kurikulum dilakukan setiap semester, di rancang jauh sebelum proses pembelajaran, serta di evaluasi setiap semester. Perencanaan kurikulum di PAUD Sulapa Eppa dilakukan dengan mengadaptasi kurikulum SISDIKNAS yang diintegrasikan dengan Visi dan Misi sekolah, serta unsur manusia pada PAUD Sulapa Eppa itu sendiri lalu di cantumkan ke dalam kurikulum. 2) Pelaksanaan kurikulum PAUD Sulapa Eppa tetap mengacu pada kurikulum nasional, namun memiliki ciri khas khusus yaitu penekanan pada empat muatan karakter: a) macca (pintar), b) malempu (jujur), c) warani (berani) dan d) magetteng (teguh pendirian) yang harus ada di setiap pelaksanaan tema pembelajaran. 3) Pengembangan kurikulum PAUD Sulapa Eppa sesuai dengan kebutuhan anak, jika memiliki kemampuan pemahaman yang cepat, maka materi pembelajaran akan di tambah. Kurikulum SISDIKNAS tidak langsung di terapkan dalam pembelajaran,
\end{abstract}


namun di analisis dan di evaluasi sesuai dengan kebutuhan anak untuk semester selanjutnya.

Kata Kunci: Kurikulum, Manajemen, PAUD Sulapa Eppa

\begin{abstract}
This study aimed to determine the process of planning, implementing or applying, and developing curriculum in Sulapa Eppa Early Childhood Education (PAUD) curriculum. The type of this research used descriptive qualitative research. The research subject was the Sulapa Eppa PAUD head master. The datawas collected through indepth interview techniques, observations and questionnaires. The results of the research showed that: 1) The curriculum was organized in every semester, it designed long before the learning process, and it was evaluated every semester. Curriculum planning in Sulapa Eppa PAUD was done by adapting the SISDIKNAS curriculum that was integrated with the school's Vision and Mission, also the human component in SulapaEppaPAUD itself and then it was included in the curriculum. 2) The implementation of the Sulapa Eppa PAUD curriculum still referred to the national curriculum, but it had a particular characteristic, that was the accentuationto four character loads: a) macca (smart), b) malempu (honest), c) warani (brave) and d) magetteng (firm of priciple) that must exist in every implementation of the learning theme. 3) The development of the Sulapa Eppa PAUD curriculum appropriated with the needs of children, if they have ability to understand quickly, then the learning material will be added. The SISDIKNAS curriculum was not directly applied in learning, but it was analyzed and evaluated according to the child's needs for the next semester.
\end{abstract}

Keywords: Curriculum, Management, PAUD Sulapa Eppa

\title{
PENDAHULUAN
}

Pendidikan Anak Usia Dini (PAUD) merupakan suatu upaya pembinaan yang ditujukan kepada anak dari rentang usia 0 - 6 tahun yang dilakukan dengan pemberian rangsangan pendidikan guna membantu anak dalam pertumbuhan dan perkembangannya baik jasmaniah maupun rohaniah agar anak memiliki kesiapan dalam memasuki pendidikan lebih lanjut (Indrijati, 2016).Pendidikan Anak Usia Dini adalah jenjang pendidikan sebelum jenjang pendidikan dasar yang merupakan suatu upaya pembinaan yang ditunjukkan bagi anak sejak lahir sampai usia enam tahun. Dalam pendidikan anak usia dini yang harus dikembangkan ialah enam aspek perkembangan. (1) Aspek fisik motorik, (2) Aspek kognitif, (3) Aspek sosialemosional, (4) Aspek moral dan agama, (5) Aspek bahasa, dan (2) Aspek seni. Dan seluruh aspek perkembangan ini harus dikembangkan sesuai dengan usia perkembangan dan pertumbuhan anak(Hasyim, 2015)

PAUD (Pendidikan Anak Usia Dini) merupakan salah satu lembaga dasar yang berfokus padapembentukan SDM (Sumber Daya Manusia) berkualitas. Hal ini sesuai dengan amanat UU No. 20 tahun 2003 mengenai SISDIKNAS (Sistem Pendidikan 
Nasional) tentang pentingnya penanganan pendidikan anak usia dini (Ridho, Markhamah, Darsinah, 2015). Trend peningkatan pertumbuhan dan perkembanganberbagai jenis lembaga PAUD terjadi pada berbagai wilayah di Indonesia. Namun, kenyataannya fenomena tersebut terkadang kurang sejalan dengan kualitas mutu layanan PAUD yang seharusnya juga semakin meningkat. Terdapat berbagai macam permasalahan yang seringkali dihadapi lembaga PAUD, mulai dari permasalahan layanan PAUD, ketersediaan sarana dan prasana, pembiayaan proses penyelenggaraan PAUD yang terkadang minim, manajemen kurikulum yang digunakan dalam lembaga PAUD, dan ketersediaan waktu dalam perencanaan penyusunan kurikulum.

Hal yang sering menjadi sorotan adalah manajemen kurikulum yang digunakan dalam lembaga PAUD. Manajemen berasal dari bahasa latinyakni kata manus (tangan) dan agree (melakukan). Kedua kata ini digabungkan menjadi manager yang berarti menangani atau mengatur sesuatu menjadi seperti apa yang diharapkan dengan memanfaatkan seluruh kemampuan yang tersedia (Kristiawan, dkk., 2017). KBBI (Kamus Besar Bahasa Indonesia) membahas bahwa kurikulum adalah keseluruhan mata pelajaran yang diajarkan pada suatu lembaga pendidikan (Tim penyusun $\mathrm{KBBI}, 2016)$. Manajemen kurikulum pada PAUD adalah proses pengelolaan secara efisien dan efektif terhadap seperangkat bahan pembelajaran yang harus dimiliki oleh peserta didik yang berusia dini (usia0-6 tahun) agar mencapai pertumbuhan dan perkembangan secara optimal. Kurikulum PAUD yang dikelola secara efisien dan efektif akan mampu mengarahkan tujuan dari kelembagaan PAUD, sehingga proses pengelolaan kurikulum wajib berpegang pada prinsip manajemen kurikulum tersebut (Suyadi, 2017). Jadi, manajemen kurikulum PAUD merupakan perencanaan pengelolaan seperangkat bahan ajar yang wajib dimiliki oleh peserta didik usia 0 hingga 6 tahun secara efisien dan efektif agar mencapai pertumbuhan dan perkembangan maksimal.

Anisa Hidayati dalam hasil penelitiannya yang berjudul manajemen kurikulum Pendidikan Anak Usia Dini di TK Ponegoro 156 Karanglewas Lor Purworkerto Barat Banyumas Tahun pelajaran2013/2014 menyatakan bahwa kegiatan manajemen kurikulum di TK Ponegoro 156 Karanglewas Lor meliputi empat proses yaitu perencanaan kurikulum, pengorganisasian kurikulum, pelaksanaan manajemen kurikulumnya, serta pengawasan dan evaluasi kurikulum. Pelaksanaan manajemen kurikulum merupakan perpaduan kultural antara manajemenprofesional (fokus pada pengembanganfungsi-fungsi manajemen) dengan manajemen kurikulum (beban manajemen terletak pada Kepala Sekolah ketika proses pengembangan kurikulumnya) (Hidayati, 2014).Peningkatankurikulum PAUDdapat dilakukan oleh pendidik atau guru, seperti melalui proses penyusunan kurikulum, perencanaan kurikulum, pelaksanaan kurikulum, dan pengembangan kurikulum yang juga dapat meningkatan kualitas lembaga PAUD. Adapun Kurikulum 2013 atau yang diatur dalam SISDIKNAS memberikan penekanan lebih pada kompetensi pemikiran yang 
berfokus pada sikap, keterampilan, dan pengetahuan (Kurniasih dan Berlin, 2015). Pada pengelolaan pendidikan, guru mempunyai otoritas penuh dalam mengembangkan kurikulum, yakni guru bebas menambah atau mengubah isi kurikulum tersebut dengan mengacu atau disesuaikan dengan karakteristik dan kebutuhan dari peserta didiknya. Tidak menutup kemungkinan apabila terjadi kolaborasi dan elaborasi antara K13 dari SISDIKNAS dengan kurikulum PAUD yang disusun oleh guru, sehingga menjadi kurikulum dengan ciri khas PAUD dan akan membentuk reputasi (personalbrand) bagi PAUD yang bersangkutan. Hal ini sejalan dengan pemaparan dari yunitasari dan Japarianto (2014) dalam jurnalnya yang berjudul analisa faktor-faktor pembentuk personal branding dari C.Y.N. Dimana, salah satu dari 6 faktor yang terbentuk adalah faktor unique. Ciri khas dari suatu produk, selain ditingkatkan perlu pula untuk di padukan dengan trend yang sedang berkembang di masyarakat, agar ciri khas tersebut tidak ketinggalan zaman, namun tidak menghapuskan ciri khas yang ada.

Hasil pre-eliminary studypeneliti di lapangan sejak bulan November hingga Desember berhasil menjumpai salah satu PAUD yang unik bernama PAUD Sulapa Eppayang berlokasi di Kabupaten Gowa Provinsi Sulawesi Selatan. Keunikan PAUD ini terletak pada implementasi kurikulumnya yang mengacu pada kurikulum PAUD Departemen Pendidikan Nasional mengenai acuan menu pembelajaran PAUD (Menu Pembelajaran Generik Tahun 2002) dengan memprioritaskan pada pengembangan karakter yang berlandaskan nilai agama dan kearifan lokal etnis Bugis-Makassar dengan konsep Sulapa Eppa (pengamalan macca na malempu (pandai dan jujur), warani na magetteng (berani dan teguh pendirian) agar menjadi tu panrita(insan kamil) serta mempertimbangkan aspek multiple intelegence.Sehingga, berdasarkan sejumlah pemaparan diatas, peneliti tertarik untuk melakukan penelitian mengenai proses penerapan manajemen kurikulum PAUDSulapa Eppa yang ditinjau dari, perencanaan, pelaksanaan, dan pengembangan kurikulum di PAUD Sulapa Eppa.

\section{METODE PENELITIAN}

Penelitian ini menerapkan pendekatan deskriptif kualitatif yakni prosedur penelitian yang menghasilkan data deskriptif berupa kata-kata tertulis yang dideskripsikan ataupun secara lisan dari orang-orang dan perilaku yang diamati dan cenderung menggunakan analisis. Penelitian kualitatif juga memperoleh hasil secara langsung dengan cara berinteraksi langsung dengan subjek yang di teliti (Saat \& Mania, (2018). Peneliti memilih pendekatan ini disebabkan oleh prosesnya yang sederhana dan memudahkan peneliti karena tidak membutuhkan pemahaman mengenai ilmu statistik yang terlalu mendalam (Sukardi, 2014). Lokasi penelitian bertempat di PAUD Sulapa Eppa yang berada di Kecamatan Somba Opu, Kelurahan Romang Polong, Kabupaten Gowa. Sumber data adalah subjek penelitian yaknikepala sekolah PAUD Sulapa Eppa (subjek tunggal penelitian). Adapun alasan pemilihan PAUD Sulapa Eppa sebagai lokasi penelitian karenapertama, memiliki 
karakteristik berupa profil manajemen kurikulum PAUD yang unikdengan ciri khas khusus dalam mengembangkan karakter peserta didikdan kedua, keterjangkauan lokasi penelitian yang berjarak relatif dekat dengan lokasi peneliti bermukim.

Pengumpulan data dilakukan melalui teknik: 1) Indepth interview terhadap kedua subjek penelitian yakni wawancara semi terstruktur. Dimana peneliti mengumpulkan data dengan menyiapkan instrument terlebih dahulu. Dengan wawancara peneliti menggunakan pedoman wawancara agar memudahkan dan mengfokuskan pertanyaan yang diajukan. Peneliti juga menggunakan alat bantu rekam untuk membantu dalam mengolah data. (Saat dan Mania, 2018), 2) Observasi menggunakan pedoman observasi yakni cara menghimpun bahan bahan keterangan dengan melakukan pengamatan langsung pencatatan yang secara sistematis terhadap gejala gejala yang dijadikan objek pengmatan manajemen kurikulum PAUD. (Harahap, 2017), 3) Angket yakni alat pengumpulan data yang berisi pertanyaanpertanyaan yang dikerjakan oleh orang yang menjadi subjek penelitian atau responden secara tertulis (Husama, dkk, 2018). dan 4) Dokumentasi yakni berbagai peralatan penunjang dalam penelitian seperti dokumentasi foto melalui kamera, video rekaman, dan lainnya).

Peneliti merupakan instrumen utama penelitian, dimana peneliti sendiri yang bertindak sebagai perencana, pengumpul data dengan mengambil data langsung melalui wawancara dan observasi, kemudian menganalisis data, menafsirkan data, dan melaporkan hasil penelitian yang diperolehnya (Kusyairy, 2018). Selanjutnya, data penelitian kemudian dianalisis dengan tahapan (Saat \& Mania, 2018): 1) Reduksi data yaitu merangkum dan menyaring data penting, 2) Penyajian data yaitu menyajikan data yang tersedia dalam bentuk uraian singkat, dan 3) Penarikan kesimpulan dan verifikasi yaitu mengambil kesimpulan dan verifikasi terhadap data yang terkumpul. Adapun pengujian keabsahan data menggunakan tahap (Suwendra, 2018): 1) Credibility (kepercayaan) yaitu peneliti berusaha mencapai credibility dengan mengajukan pertanyaan apakah proses dan hasil penelitian dapat dipercaya dan diterima oleh pembaca dengan menggunakan teknik berikut: a) Peer debriefing (diskusi) yaitu membicarakan hasil penelitian dengan orang yang tidak berkepentingan dalam penelitian agar hasilnya objektif. Peneliti akan berdiskusi dengan informan penelitian seperti teman subjek. b) Triangulasi yaitu mengecek kebenaran data dengan mencari informasi dari berbagai sumber dengan cara dan waktu berbeda. Sumber data adalah subjek, teman subjek, dan dosen pembimbing skripsi subjek. 2) Transferbility (keteralihan) yaitu peneliti berusaha menyajikan data yang kaya deskripsi dan lebih rinci dengan mengenal subjek dan keadaan lapangan dengan baik, sehingga kehadiran peneliti tidak lagi mempengaruhi situasi. 3) Dependability (ketergantungan) yaitu peneliti berusaha untuk selalu berdiskusi dan mengkonsultasikan segala proses penelitiannya dengan pakar secara bertahap, khususnya dengan sesama rekan peneliti. 


\section{HASIL PENELITIAN DAN PEMBAHASAN}

Proses penerapan manajemen kurikulum PAUD Sulapa Eppa ditinjau dari perencanaan, pelaksanaan, dan pengembangan kurikulum di PAUD Sulapa Eppa dijabarkan sebagai berikut:

\section{Perencanaan (Planning)}

Subjek penelitian menjelaskan bahwa perencanaan kurikulum yang di gunakan di PAUD Sulapa Eppa sudah di rancang secara matang jauh sebelum proses pembelajaran berjalan dan uniknya orang tua berpartisipasi dalam perencanaan kurikulum.Fatimah dan Rohmah (2016) mendukung pernyataan ini, dimana perencanaan (planning) dianggap sangat penting karena dalam menjalankan suatu kegiatan pasti terdapat perencanaan untuk merencanakan mulai dari materi pembelajaran, waktu yang akan dilaksanakan serta alat yang digunakan atau diperlukan dalam proses pembelajaran. Selain itu, terdapat dua pandangan mengenai perencanaan kurikulum. Pertama, yang dikemukakan oleh para behavioris mengatakan bahwa rancangan kurikulum didasarkan pada hal-hal yang diperlukan. Kedua, pandangan yang dikembangkan oleh para ahli perkembangan anak yang menyatakan bahwa rancangan harus berdasarkan telaah psikologi perkembangan yang mengatakan bahwa anakmerupakan"pelajar" aktif dalam menelaah lingkungan dan berbagai pengalaman hidupnya (Suyadi, 2016)

\section{Pelaksanaan (implementing)}

Hasil proses observasi dan wawancara terhadap subjek penelitian mengenai pelaksanan kurikulum Pendidikan Anak Usia Dini di PAUD Sulapa Eppa sudah berjalan sesuai sebagaimana mestinya, pemilihanisi dan organisasi materi pembelajaran sesuai indikator dan kompetensi dasar pada kurikulum. Penyusunan pembuatan kurikulum di rencanakan terlebih dahulu dengan cara mengambil dari DIKNAS, visi misi sekolah dan unsur manusia Sulapa Eppa di masukkan ke dalam kurikulum. PAUD Sulapa Eppa juga menyusun kurikulum setiap semester.Penyusunankurikulum dilakukan jauh sebelum proses pembelajaran dan evaluasi dilakukan tiap semesternya.

Secara umum pelaksanaan isi kurikulum di PAUD Sulapa Eppa sama dengan kurikulum nasional, hanya saja di Sulapa Eppa dalam kurikulumnya memiliki ciri khas khusus yaitu ada empat muatan yang menjadi penekanan muatan karakter, (1) macca (pintar), (2) malempu (jujur), (3) warani (berani) dan (4) magetteng (teguh pendirian). Setiappelaksanaan suatu tema pembelajaran minimal harus ada satu penekanan muatan karakter tersebut. Pelaksanaan kurikulum di PAUD Sulapa Eppa di sesuaikan dengan kebutuhan siswa, akan tetapi siswa yang memiliki pemahaman yang lebih cepat materi pembelajarannya di tambah sesuai kemampuan anak.

Penggunaan metode dalam melakukan evaluasi terkait dengan perkembangan anak. Di PAUD Sulapa Eppa, orang tua siswa ikut serta dalam perencanaan kurikulum. Pelaksanaan dan penggunaan media pembelajaran sesuai dengan tema 
pada kurikulum, alokasi waktu yang digunakan dalam pembelajaran sudah sesuai dengan waktu yang dicantumkan di dalam kurikulum. Desain kurikulum sudah terencana dan terorganisir sehingga hasilnya efektif, Kegiatan, materi dan bahan ajar yang digunakan sudah sesuai dengan silabus dan isi program kurikulum sehingga memudahkan siswa untuk menguasai materi pembelajaran didalamnya mencakup pengembangan sikap, keterampilan dan pengetahuan.

Hal ini sesuai dengan hasil penelitian Fatimah dan Rohmah (2016) bahwa pelaksanaan (implementing) merupakan fungsi manajemen yang terpenting dan paling dominan dalam proses manajemen. Dimana, minimal dalam setiap pelaksanaan suatu tema pembelajaran harus ada pulasuatu penekanan muatan karakter tersebut.Secara umum pelaksanaan isi kurikulum di PAUD Sulapa Eppa sama dengan kurikulum nasional, hanya saja PAUD ini mempunyai keunikan yang terletak pada implementasi kurikulumnya yang mengacu pada kurikulum PAUD Departemen Pendidikan Nasional mengenai acuan menu pembelajaran PAUD (Menu Pembelajaran Generik Tahun 2002) dengan memprioritaskan pada pengembangan karakter yang berlandaskan nilai agama (pengembangan ketakwaan kepada ALLAH SWT) dan kearifan lokal etnis Bugis-Makassar dengan konsep Sulapa Eppa (pengamalan macca na malempu (pandai dan jujur)), warani na magetteng (berani dan teguh pendirian) agar menjadi tu panrita(insan kamil)) serta mempertimbangkan aspek multiple intelegence(kecerdasan majemuk) seperti linguistic, logical mathematical, interpersonal, interpersonal, naturalis, musical, spasial, body kinestetik, dan existensialist).

\section{Pengembangan (developing)}

Subjek penelitian menjelaskan bahwa proses pengembangan kurikulum di PAUD Sulapa Eppa baru berjalan selama satu semester, yakni berlangsung sejak bulan Agustus hingga Desember.Pada semester satu ini banyak hal yang akan dikembangkan secara maksimal dan menjadi dasar evaluasi dari PAUD Sulapa Eppa untuk melakukan berbagai penyempurnaan di semester yang akan datang. Interaksi guru dengan siswa selama proses pembelajaran cukup baik, Dimana di PAUD Sulapa Eppa memiliki siswa 8 orang yang berusia 2-6 tahun. Uuntuk pelaksanaan pembelajaran full di kelas hanya untuk TK (Taman Kanak-Kanak usia 4 hingga 6 tahun), dan KB (Kelompok Bermain usia 2hingga 3 tahun) tetap memakai kurikulum hanya saja bermain dan alat permainannya disesuaikan dengan kurikulum. Anak usia KB tidak harus ikut pembelajaran dalam kelas, tetapi tetap mengacu pada kurikulum yang ada. Sedangkan anak usia TK wajib mengikuti pembelajaran di dalam kelas. Selanjutnya kurikulum harus disesuaikan dengan kebutuhan anak. Kurikulum dari SISDIKNAS tidak serta merta langsung di terapkan tapi harus di analisis dan disesuaikan dengan kebutuhan anak, dalam merancang penggunaan kurikulum, sekolah meminta orang tua siswa untuk berpatisiasi, serta siswa di observasi untuk mengetahui kebutuhan anak semester selanjutnya. 
Pernyataan ini di dukung oleh Bahri (2011) yang menilai bahwa pengembangan (developing) kurikulum tidak hanya merupakan abstraksi akan tetapi mempersiapkan berbagai contoh dan alternatif untuk tindakan yang merupakan inspirasi dari beberapa ide dan penyesuaian-penyesuaian lain di masa mendatang yang di anggap penting bagi lembagaatau institusi pendidikan.

\section{SIMPULAN}

Kesimpulan dari hasil penelitian ini adalah sebagai berikut: (1) Perencanaan kurikulum dilakukan secara unik yang dilakukan setiap semester dan di rancang jauh sebelum proses pembelajaran serta evaluasi dengan melibatkan peran orangtua siswa. Perencanaan kurikulum di PAUD Sulapa Eppa dilakukan dengan cara mengambil dari DIKNAS, visi misi sekolah, dan unsur manusia Sulapa Eppa itu sendiri yang kemudian di cantumkan ke dalam kurikulum; (2) Pelaksanaan kurikulum di PAUD Sulapa Eppa tetap mengacu pada kurikulum nasional, hanya saja di Sulapa Eppa dalam kurikulumnya memiliki ciri khas khusus yaitu ada empat muatan yang menjadi penekanan muatan karakter, (1) macca (pintar), (2) malempu (jujur), (3) warani (berani) dan (4) magetteng (teguh pendirian). Yang harus ada di setiap pelaksanaan pembelajaran minimal dalam suatu tema pembelajaran harus ada satu penekanan muatan karakter tersebut; dan (3) Pengembangan kurikulum PAUD Sulapa Eppa di kembangkan sesuai dengan kebutuhan anak. Anak yang memiliki kemampuan pemahaman yang cepat di tambah materi pembelajarannya. Kurikulum dari SISDIKNAS tidak serta merta langsung di terapkan dalam pembelajaran tapi harus di analisis dan di evaluasi sesuai dengan kebutuhan anak untuk semester selanjutnya.

\section{DAFTAR PUSTAKA}

Al-Tabany, B.I.T.(2011). Desain Pengebangan Pembelajaran Tematik Bagi Anak Usia Dini Tk / Ra \& Anak Usia Kelas Awal Sd/Mi. Jakarta: Prenamedia Grup.

Bahri, Syamsul. (2011). Pengembangan Kurikulum Dasar dan Tujuannya.Jurnal IImiah Islam Futura (Online), Vol. 11 No. 1 Tahun 2011.(http://raniry.ac.id/index.php/islamfutura/article/view/61\&ved=2ahUK EwjFnJPAgMjfAhUMYo8KHeBVD34QFJAAegQIBHAB\&usg=AOvVaw0gDuYw6dp U5Tfn5, di akses 29 Desember 2018).

Fatimah, D.F. dan Rohmah, N. (2016). Pola Pengelolaan Pendidikan Anak Usia Dini di PAUD Ceria Gondangsari Jawa Tengah. Manageria: Jurnal Manajemen Pendidikan Islam(Online),Vol. 1 No. 2 Tahun 2016. (https://www.google.com/url?sa=t\&source=web\&rct=j\&url=http://ejournal.ui nsuka./manageria/article/download/1338/1187\&ved=2ahUKEwjv4ausrsffAh 
UPEnIKHXICCooQFjABegQIAhAB\&usg=AOvVaw05BM-EV-uwUiyjR2GiUN6L, di akses 29 Desember 2018).

Harahap, S.M.I. (2017). Upaya Meningkatkan perkembangan moral anak usia 5-6 tahun melalui metode bercerita di TK Nurul Ihsan Ilmi Medan Tembang. Skripsi publikasi(Online).(http://text-id.123dok.com/document/q5ovoxjz-skripsi-itamelina-sari-harahap-nim-38-13-3-008.html, di akses 29 Desember 2018).

Hasyim, S. L. (2015). Pendidikan Anak Usia Dini (PAUD) dalam Perspektif Islam. Jurnal Lentera: Kajian Keagamaan, Keilmuan, Dan Teknologi (Online), Vol. 1 No.2

Tahun 2015.(http://www.google.com/url?sa=t\&source=web\&rct=j\&url=https://medi a.neliti.com/media/publication/177274-ID-pendidikan-anak-usia-dini-pauddalam per.pdf\&ved=2ahUKEwi20uShrMffAhUF3o8KHUbxCMAQFjACegQICBAB\&usg= AOvVaw2q5HZHd2R761EUXQjxF-7T, di akses 30 Desember 2018).

Hidayanti,A. (2014).Manajemen Kurikulum Pendidikan Anak Usia Dini Di TK Diponegoro 156 Karanglawas Lor Purwokerto Barat Banyumas Tahunajaran 2013/2014. Skripsi publikasi (Online).(http://repository.iainpurwokerto.ac.id/1223/2/Cover\%2C\%20Bab\% 20I\%2C\%20Bab\%20V\%2C\%20Daftar\%20Pustaka.pdf, di akses 29 Desember 2018).

Husamah, P., Yuni, R.,Arina, S., dan Puji. (2018). Belajar dan Pembelajaran. Malang: UMM Press.

Indrijati, H.(2016). Psikologi Perkembangan dan Pendidikan Anak Usia Dini. Jakarta: Prenadamedia Group.

Kristiawan, M., Safitri, D., dan Lestari, R. (2017).ManajemenPendidikan. Yogyakarta: Deepublish.

Kurniasih, I. dan Sani, B. (2017). Pendidikan Karakter: Internalisasi dan Metode Pembelajaran Disekolah. Jakarta:Kata Pena.

Kusyairy, U. (2018). Fenomena Irrelevant Topics pada Skripsi (Dinamika Psikologis Mahasiswa yang Sedang dan Telah Mengerjakan Skripsi pada Fakultas Tarbiyah dan Keguruan UIN Alauddin Makassar).Penelitian LITAPDIMAS. Tidak diterbitkan. Makassar: Kementerian Agama.

Latief, M., Zubaidah, R., Zulkhairina, dan Afandi, M.(2013). Orientasi Baru Pendidikan Anak Usia Dini: Teori danAplikasi.Jakarta: Prenadamedia Group.

Ridho, R., Markhamah, dan Darsinah.(2015). Pengelolaan Pembelajaran Pendidikan Anak Usia Dini (PAUD) di KB “Cerdas” Kecamatan Sukorejo Kabupaten Kendal. Jurnal Penelitian Humaniora, Vol. 16, No. 2, Tahun 2015:59-69 
(https://id.scribd.com/document/365409785/1857-3424-1-SM-1 (Online), di akses 29 Desember 2018).

Saat, S. dan Mania, S. (2018). Pengantar Meodologi Penelitian. Makassar: Sibuku.

Sukardi. (2014). Metodologi Penelitian Pendidikan. Jakarta: Bumi Aksara.

Suwendra, Wayan. I. (2018). Metodologi Penelitian Kualitatif dalam IImu Sosial,Pendidikan, Kebudayaan, dan Keagamaan. Bandung: Nilacakra Publishing House.

Suyadi. (2017). Manajemen Paud TPA-KB-TK/RA. Yogyakarta: Pustaka Pelajar.

Tim penyusun KBBI. (2016). Kamus Besar Bahasa Indonesia edisi ke-5. Jakarta: Badan Pengembangan dan Pembinaan Bahasa, Kementerian Pendidikan dan Kebudayaan Republik Indonesia.

Yunitasari, C., dan Japarianto, E. (2013). Analisa Faktor-Faktor Pembentuk Personal Branding dari C.Y.N. Jurnal Manajemen Pemasaran Petra (Online),Vol. 1 No. 1 Tahun 2013. (https://media.neliti.com/media/publications/133264-IDanalisa-faktor-faktor-pembentuk-personal.pdf, di akses 29 Desember 2018). 